\title{
ENHANCING OPTICAL ABSORPTION IN InP AND GaAs UTILIZING PROFILE ETCHING
}

\author{
Sheila G. Bailey \\ NASA Lewis Research Center, Cleveland, OH 44135 \\ Navid S. Fatemi and Geoffrey A. Landis, \\ Sverdrup Technology, Inc., NASA Lewis Research Center, Brook Park, OH 44142
}

\begin{abstract}
The current state of profile etching in GaAs and InP is summarized, including data on novel geometries attainable as a function of etchant temperature, composition, and rate, substrate orientation and carrier concentration, and oxide thickness between substrate and photoresist. V-grooved solar cells have been manufactured with both $\mathrm{GaAs}$ and $\mathrm{InP}$, and the improved optical absorption demonstrated. Preferred parameters for various applications are listed and discussed.
\end{abstract}

\section{INTRODUCTION}

Profiling techniques have played a large role in increasing efficiencies in silicon solar cells in a variety of ways. Short circuit current is increased because the reflected incident light is redirected to the surface. Other advantages include enhanced absorption [1], light trapping [2], reducing grid shadowing [3], and advanced junction/contact geometries $[4,5]$. The extension of these techniques to the III-V materials has been slow, principally because anisotropic etching in the III-Vs is more complicated than on silicon [6]. The (111) plane is chemically different from the (111) plane, and both etching and deposition behave differently on these surfaces.

\section{ANISOTROPIC ETCHING}

The process of etching profiles in III-V materials requires $(i)$ noting type and carrier concentration of substrate, and oxide layer between photoresist and substrate, (ii) masking the surface with photoresist stripes, aligned to the required crystallographic direction, (iii) selecting an appropriate anisotropic etchant, and (iv) carefully monitoring etch conditions such as time, temperature, and illumination. In compound semiconductors such as $\mathrm{GaAs}$ and $\mathrm{InP}$, the [011] and [011] alignments on the (100) surface are non-identical, and grooves oriented along [01I] will etch with significantly different profiles than grooves oriented perpendicular to this direction. It is important to note that there are two inconsistent conventions for the flat location on InP (100) wafers. Fig. 1 illustrates two possible geometries in both $\mathrm{GaAs}$ and InP with reference to a typical wafer alignment.

The conditions required to produce V-groove solar cells (see Fig. 2) in both GaAs [7] and InP [8] require careful control of the lateral undercut etch rate with respect to the vertical etch rate. The objective is to produce grooves without a flat plateau at the peak. This requires that the photoresist mask be undercut by the etch. For the solar cells produced here, the mask lines are $\sim 4$ microns in width, and the groove periodicity was 7 to 8 microns. The wafer orientation is $(100)$.

A variety of anisotropic etchants can be used with GaAs [9] and InP [10], however, only limited etchants and conditions will produce the triangular saw-toothed structure. When the photoresist lines are parallel to the [011] direction $\mathrm{GaAs}$ can be etched to a perfect saw-tooth by the use of a Caros etchant, consisting of $5: 1: 1$ proportions of $\mathrm{H}_{2} \mathrm{SO}_{4}: \mathrm{H}_{2} \mathrm{O}_{2}: \mathrm{H}_{2} \mathrm{O}$, respectively. At a temperature of $24^{\circ} \mathrm{C}$ with a native oxide layer between substrate and photoresist, the required etchant time is two minutes [11]. Anisotropic etching in GaAs is insensitive to type of dopant and carrier concentrations, however, etching rates can be altered by varying the oxide thickness between photoresist and substrate. 


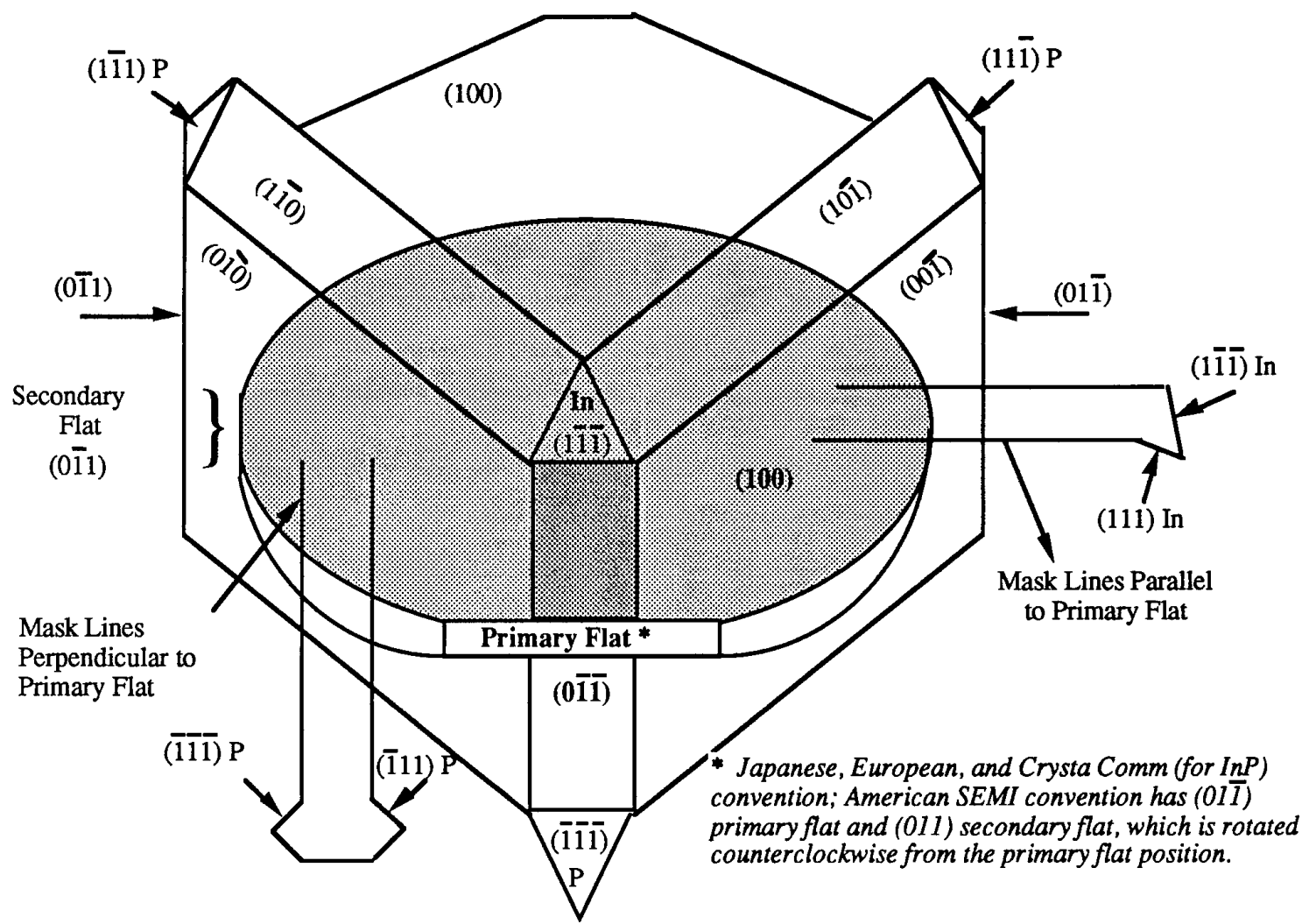

Fig. 1. Orientation of III-V wafer and masklines for desired geometries

Anisotropic etching of InP is markedly different. The ratio of lateral undercutting to vertical depth is strongly dependent on the type of dopant and the substrate carrier concentration, with structures becoming isotropic at high carrier concentrations and etchant times. This is clearly visible in the scanning electron microscope (SEM) crosssectional views, where the same etchant produces isotropic (Fig. 3) and anisotropic (Fig. 4) etching in material of different doping.

The photoresist stripes are visible at the tops of the grooves. In low doped (E16-E17) p-type InP, perfect (111) triangular sawtooth grooves can be produced with

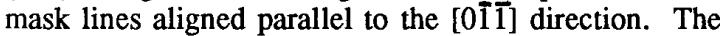
preferred Lewis etchant is $\mathrm{HBr}: \mathrm{H}_{2} \mathrm{O}_{2}: \mathrm{HCl}$ in $10: 1: 1$ proportions respectively. An etch temperature of $-20^{\circ} \mathrm{C}$ with a native oxide layer between substrate and photoresist requires 6 minutes of etching time. Without the native oxide, the photoresist is not undercut, and flat-toped grooves are produced. It should be noted that the etchant temperature must be carefully monitored with this etchant since bromine gas is released at elevated temperatures. A simple $\mathrm{HCl}$ etch produced low-angle V-grooves [12]. The etchant dependent selectivity is illustrated in Fig. 5. The (111) V-groove was submerged in the Lewis etchant at $0^{\circ}$ $\mathrm{C}$ for 2.5 minutes, followed by a dip in $\mathrm{HCl}$ for 15 seconds at room temperature. As shown in the figure, the (113) plane closest to the photoresist was formed by the $\mathrm{HCl}$ etch, while the (111) plane immediately below was formed by the Lewis etchant.

When the mask lines are oriented perpendicular to the [0iㅣ] direction, different crystalline planes emerge. In both $\mathrm{GaAs}$ and InP the undercutting is much more rapid. The etch profile in InP is again sensitive to the substrate dopant concentrations. Fig. 6 and Fig. 7 illustrate this effect. Fig. 8 shows the comparative structure in GaAs, which is insensitive to dopant type or concentration. In $\mathrm{GaAs}$ the orientation results in very clearly defined "hex" shaped grooves [6]. 


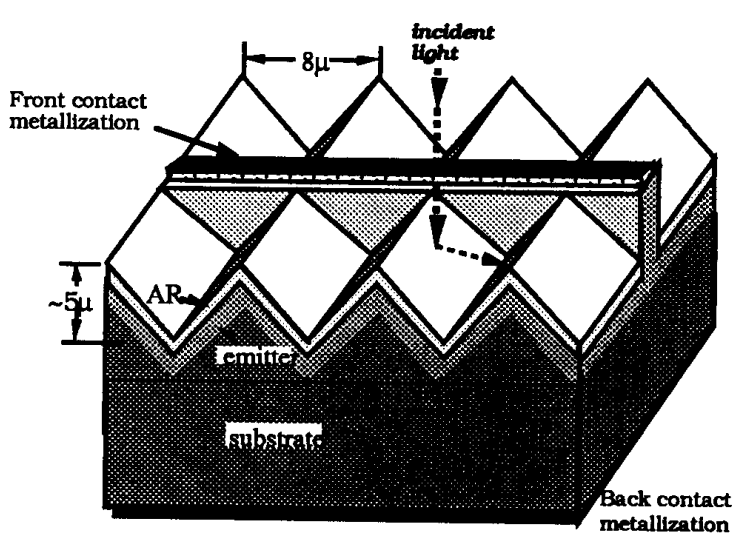

Fig. 2. Schematic of V-grooved III-V solar cell (not to scale)

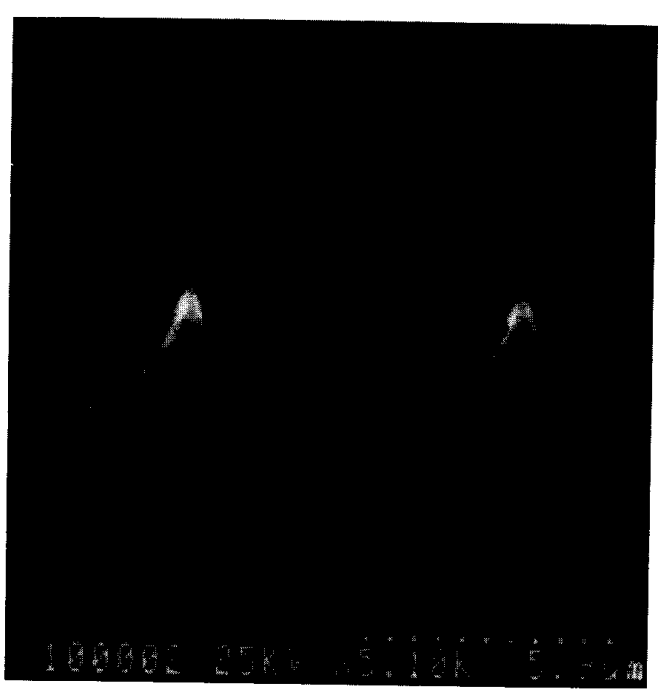

Fig. 3. InP, Zn:1E18 $\mathrm{cm}^{-3}$, with mask lines parallel to the primary flat, etched 1 minute at $-20^{\circ} \mathrm{C}$

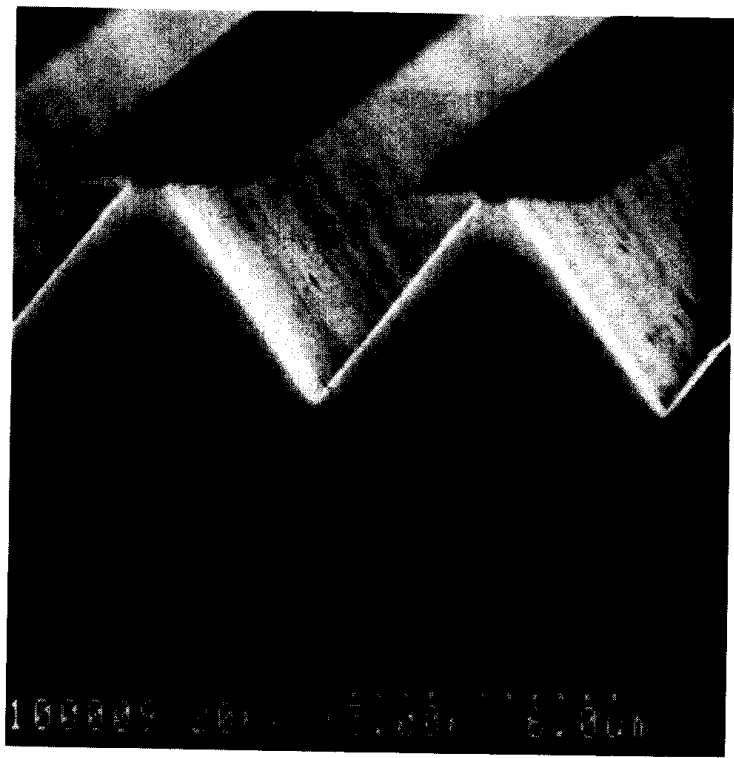

Fig. 4. InP, Zn: $2 E 16 \mathrm{~cm}^{-3}$, with mask lines parallel to the primary flat, etched 6 minutes at $-20^{\circ} \mathrm{C}$

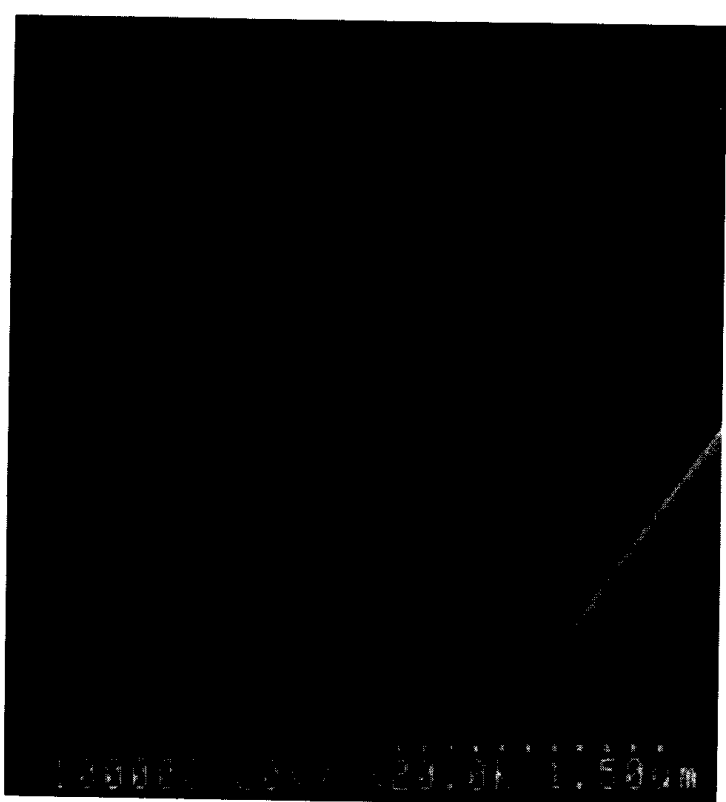

Fig. 5. InP, Zn:2E16 $\mathrm{cm}^{-3}$, with mask lines parallel to the primary nat, etched 2.5 minutes at $0^{\circ} \mathrm{C}$ in the Lewis etchant and 15 seconds in $\mathrm{HCl}$ at $24^{\circ} \mathrm{C}$ 


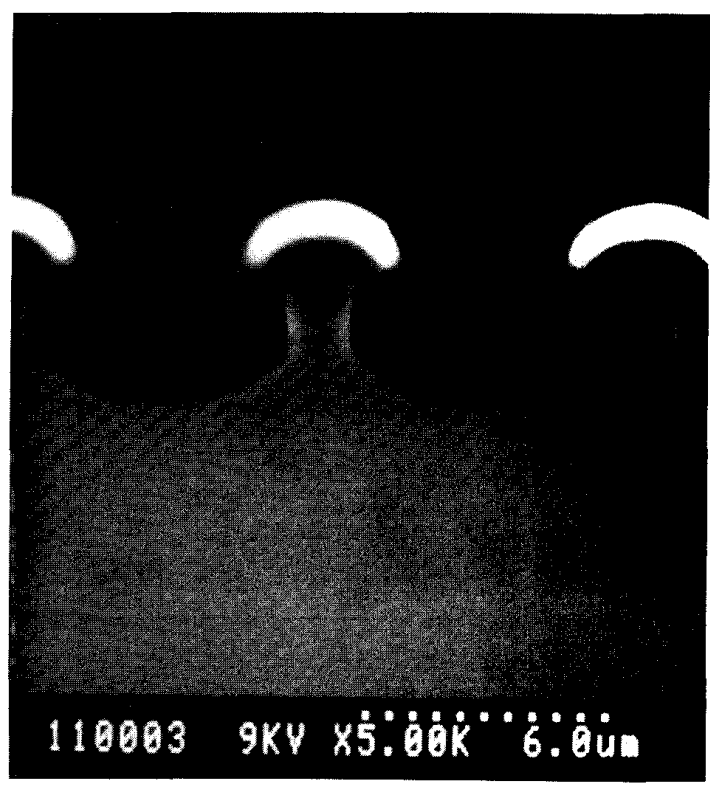

Fig. 6. InP, Zn:4E17 $\mathrm{cm}^{-3}$, with mask lines perpendicular to the primary flat, etched 1.5 minutes in the Lewis etchant at $-20^{\circ} \mathrm{C}$

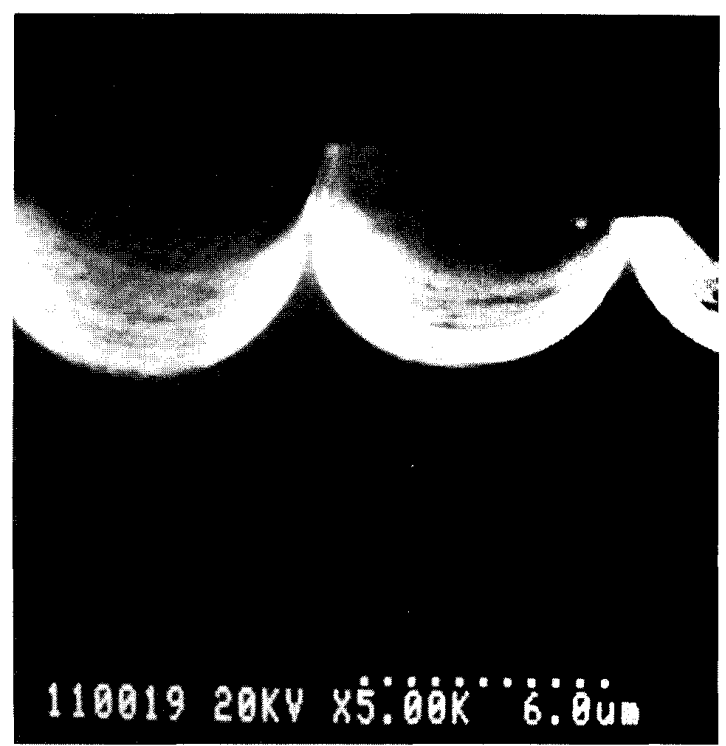

Fig. 7. InP, Zn:1.5E18 $\mathrm{cm}^{-3}$, with mask lines perpendicular to the primary flat, etched 1.5 minutes in the Lewis etchant at $-20^{\circ} \mathrm{C}$

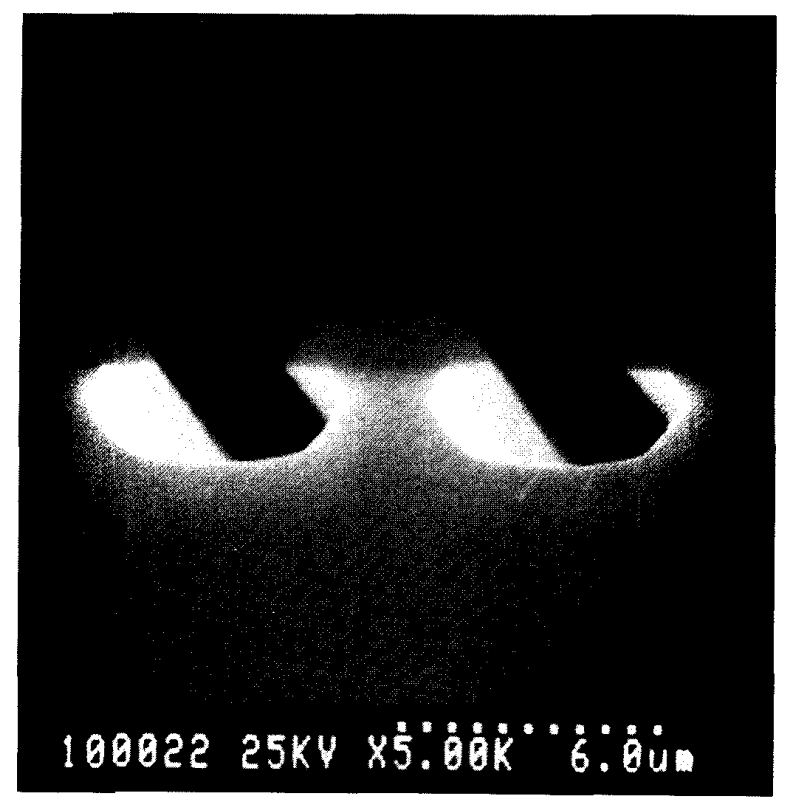

Fig. 8. GaAs, Zn:1E18 $\mathrm{cm}^{-3}$, with mask lines perpendicular to the primary flat, etched 1 minute in the Caros etchant at $30^{\circ} \mathrm{C}$

\section{DISCUSSION}

The reflectivity as a function of wavelength for ARcoated planar and V-grooved GaAs is illustrated in Fig. 9. The v-grooved surface shows a significant reduction in the total reflectivity over the solar spectrum.

Similar results have been obtained in InP [8] Fabrication of V-groove solar cells has been limited; however, results for GaAs, as illustrated in Fig. 10, indicate the potential rewards of developing such cells.

InP V-groove cells have been fabricated by means of closed ampoule diffusion [8], indium tin oxide (ITO) deposition and hydrogen plasma. In all cases an increased short circuit current density is realized with the V-groove. Difficulty still remains in achieving the open circuit voltage of the planar control cell. 


\section{CONCLUSIONS}

Recent advances in silicon solar cell efficiencies highlight the importance of improved optical coupling [13]. Both GaAs and InP exhibit similar gains in short circuit current utilizing the V-groove structure $[7,8]$. The advantages produced by the $\mathrm{V}$-grooved structure are: reduced surface reflection due to double-reflection of normally incident light, enhanced absorption produced by oblique passage of light through the cell, improved radiation tolerance due to carriers being produced closer to the junction, and the possibility of manufacture of ultrathin, light-trapping structures with high performance and radiation tolerance.

\section{ACKNOWLEDGEMENTS}

The authors would like to acknowledge the assistance of Tim Gessert at the Solar Energy Research Institute for completion of the cell structures for the ITO/InP and hydrogen plasma InP.

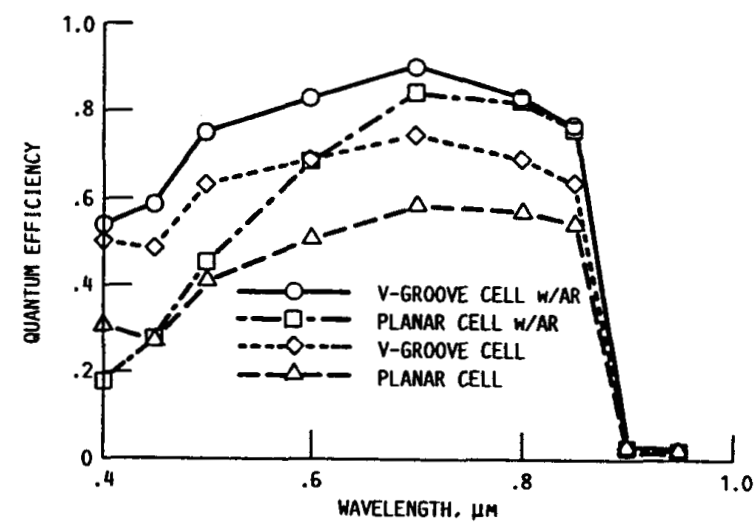

Fig. 10. Quantum efficiency as a function of wavelength for the $V$-groove and planar GaAs cells with and without an antireflective coating. 


\section{REFERENCES}

1. A. W . Blakers and M. A . Green, Appl. Phys. Lett. 48 (3), 1986.

2. G. A. Landis, Solar Cells 29, 1990.

3. P.G. Borden and R.V. Walsh, Appl. Phys. Lett. 41, 649-651, 1982.

4. R. M. Swanson, Solar Cells 17, 1986.

5. M. A. Green, Int'l PVSEC 3, 1987.

6. S. G. Bailey, G. A. Landis, and D. M. Wilt, $J$. Electrochem. Soc., 136, No. 11, 1989.

7. S. G. Bailey, N. S. Fatemi, D. M. Wilt, and G. A. Landis, Proceedings of the European Space Power Conference, 1989.

8. S. G. Bailey, N. S. Fatemi, G. A. Landis, D. Brinker, M. Faur, and M. Faur, Proceedings of the Second Int. Conf. on InP and Related Materials, 1990.

9. S. Adachi and K. Oe, J. Electrochem. Soc., 130, No. $12,1983$.

10. S. Adachi and H. Kawaguchi, J. Electrochem Soc., 128, No. 6, 1981 .

11. S. G. Bailey, G. A. Landis, D. M. Wilt, Proceedings of the Ninth Space Photovoltaic Research and Technology Conf., 1988.

12. S. G. Bailey, N. S. Fatemi, G. A. Landis, P. P. Jenkins, Proceedings of the Eleventh Space Photovoltaic Research and Technology Conf., 1991.

13. M. A. Green, Int'l PVSEC 5, 1990. 